\title{
Antivirulence effects of pomegranate peel extracts on most common urinary tract infection pathogens in pregnant women
}

\author{
Wafaa Sadeq Al-Wazni \& Bashair Sami Hadi
}

Karbala University, College of Science, Department of Biology, Iraq.

(Submitted: 20 September 2015 - Revised version received: 23 September 2015 - Accepted: 3 October 2015 - Published online: Autumn 2015)

\begin{abstract}
Objective This study includes the investigation of antibacterial and antivirulence activities of three types of pomegranate peel extracts and then determines the interaction between the extracts and antibiotic in vitro.

Methods The ability of most common isolated bacteria from urinary tract infection (UTI) to produce different virulence factors were tested and the effect of plant extracts on virulence factors were determined; in addition the correlation between extracts and antibiotics were evaluated by using fractional inhibitory concentrations.

Results The inhibition zones diameters of the pomegranate peel extracts against most common isolated bacteria (Staphylococcus aureus and Escherichia coli) increase significantly with increase in concentrations. There is no effect of the extracts on the ability of studied bacteria to produce hemolysin and protease enzymes, while both studied bacteria lost its ability to produce $\beta$-lactamase enzyme after treating with MIC. In addition, extracts were affected largely on adherence activity and biofilm forming ability of tested bacteria. The results found that the pomegranate peel extracts effect alone against pathogenic bacteria was good than they interacted with antibiotics, in most of the results. Conclusion The alcohol extract was the best solvent in its effects on bacterial pathogen and its effect was largely on the ability of the studied bacteria to form biofilm and adhesion on the epithelial cell. The pomegranate peel extracts were high synergism with some antibiotics against pathogenic bacteria.

Keywords pomegranate peel extract, antivirulence effect, interaction with antibiotic
\end{abstract}

\section{Introduction}

Urinary tract infection (UTIs) is an injury resulting from the presence and the growth of microorganism in different parts of the urinary tract, so it could be defined as the colonization of and invasion of the structures in the urinary tract by micro-organisms. ${ }^{1}$ In human, the urinary tract is one of the most common sites of bacterial infection and most case of UTI caused by bacteria which ascend from the perineum, and the reason of the ascent of bacteria raised by conditions like pregnancy. ${ }^{2,3}$ UTIs are the most common problem during pregnancy as result of physiologic changes which are related to pregnancy that make healthy women more susceptible to acquired various injury. ${ }^{4}$ UTIs are caused by different type of gram positive and negative bacteria like Escherichia coli, Klebsiella species, Proteus mirabilis, Pseudomonas aeruginosa, Enterococcus, Staphylococcus, and Streptococcus agalactiae. ${ }^{5}$ The isolate bacteria produce deferent virulence factors which play essential roles in pathogenicity of these bacteria such as hemolysin (is an important virulence factor attached with especial receptors on the erythrocytes wall then making pours in the cell wall so the erythrocytes will lyse), $\beta$-lactamase (enzyme that works to destroy the $\beta$-lactam ring of antibiotic and causing the loss of effectiveness and contain serine amino acid in their hydroxyl group which represented the active site of this enzyme). ${ }^{6}$ Pathogen adhesion to the host tissue is regarded as an important initiating step in many types of infection because it helps the bacteria to resist the defense mechanism in the body, ${ }^{7}$ and biofilm formation (a slimy layer with embedded micro colonies) is most important and widespread mode for increase pathogenicity of the microorganism and helps bacteria to resist the surrounding environment condition and antibiotic concentration.

Some pathogens which are responsible for UTI are resistance to different types of antibiotic therefore relatively limited choice of antimicrobial agents can eliminate from the body so has become necessary to work to find a new techniques more effective for the treatment of infection caused by drug-resistant microorganism. Many types of medicinal plants contain various components some of which can operate in synergy with antibiotic but others are able to sensitize the pathogen to antibiotic. ${ }^{9}$ Pomegranate is one of the medicinal plants used in medicine for treatment of several disease, which was one of the oldest fruits that have not changed much through the history of man and regarded as an important source of phenolic compounds, including hydrolysable tannins, which possess high antioxidant activity. ${ }^{10}$ The screening of medicinal plant extracts for interactions with antibiotics is expected to provide chance to determine inhibitors that may benefit medicine. ${ }^{11}$

The purpose of this study was to find a safety method to reduce pathogenicity of high virulence pathogenic bacteria responsible for UTI by using natural material and attempt to find a safety method to solve the problem of multi-drug resistance pathogen.

\section{Materials and Methods}

\section{Isolation and diagnosis of bacteria}

One hundred morning midstream urine samples were collected from pregnant women attending Maternity and Women's Hospital in Karbala Province during December 2011 to March 2012. The isolated bacteria were diagnosed biochemically according to methods described by Collee et al. ${ }^{12}$ and Baron et al. ${ }^{13}$ Then the diagnosed bacteria were confirmed by APi20E and Api Staph system accomplished according to manufacturer's instructions. The isolated bacteria used in the study were chosen according to their ability to give deep violet color on the wall and bottom of the test tubes, which was used to determine the biofilm forming as described by Mathur et al. ${ }^{14}$ 
2. Ability of isolated bacteria to produce virulence factors

Blood agar plates and skim milk agar plates were used to determine the ability of isolated bacteria to produce hemolysin and protease enzyme, respectively, as described by Collee et al. ${ }^{12}$ and Baron et al. ${ }^{13}$ The $\beta$-lactamase production was prepared according to WHO. ${ }^{15}$ The adherence activity for studied bacteria was carried out according to Svanborg et al. ${ }^{16}$ In addition we screwed isolates for their ability to form biofilm by tube and tissue culture plant methods as described by Mathur et al. ${ }^{14}$ and Maldonado et al. ${ }^{17}$

\section{Plants extracts}

Plant extracts (aqueous, alcohol, and acetone) were prepared according to Ahmed et al. ${ }^{18}$ and Al-jboriy et al. ${ }^{19}$ Then stock solution was prepared for each extract by dissolving $1 \mathrm{~g}$ of dry extract with $10 \mathrm{ml}$ of distilled water, so the final concentration of extract would be $0.1 \mathrm{~g} / \mathrm{ml}$, from this solution other concentrations were prepared $(0.01-0.1) \mathrm{g} / \mathrm{ml}$, which was used to determine the antibacterial activity of peel extracts against $S$. aureus and E. coli bacteria by agar well diffusion method as mentioned by Egharevba et al. ${ }^{20}$ but agar dilution method was used to detect minimum inhibitory concentration (MIC) of the plant extracts according to NCCLS. ${ }^{21}$ The extracts were subjected to phytochemical screening according to Ling et al. ${ }^{22}$

\section{Effect of pomegranate peel extracts on the bacterial vir-} ulence factors

MIC of each extract was added to the bacterial suspension, and all tests were made as mentioned in step 2 .

\section{Combination studies}

The combined antimicrobial activity of the pomegranate peel extracts and antibiotics were done by evaluating the fractional inhibitory concentrations (FIC) as described by Manda et al..$^{23}$

$$
\begin{aligned}
\text { FIC }(\text { antibiotic })= & \text { MIC of antibiotic in combination/MIC } \\
& \text { of antibiotic alone } \\
\text { FIC (extract) }= & \text { MIC of extract in combination/MIC of } \\
& \text { extract alone }
\end{aligned}
$$

Then the interactions between the antibiotics and the peel extracts were evaluated by using the FIC indices as described by Pankey et al. ${ }^{24}$ and Kamatou et al. ${ }^{25}$ which were calculated by using the formula:

FIC index $=\Sigma$ FIC $=$ FIC $($ antibiotic $)+$ FIC $($ plant extract $)$

The combinations were classified as synergistic (FIC indices were $<1$ ), additive (FIC indices were 1 ), indifferent (FIC indices were between 1 and 2), and antagonistic (FIC indices were $>2$ ).

\section{Statistical analysis}

Data analysis of variance was carried out by SAS. LSD was used to compare mean at 0.0001 . $^{26}$

\section{Result and Discussion}

\section{Frequency of urinary tract pathogens in pregnant women}

Fifty-two bacterial isolates were isolated in this study, gram-positive bacteria $43(83 \%)$ occurred more frequently than gram-negative bacteria $9(18 \%)$ where S. aureus $20(39 \%)$ and $E$. coli $6(11 \%)$ were the commonest offending isolated as shown in Fig. 1. First, this might be due to environment, the

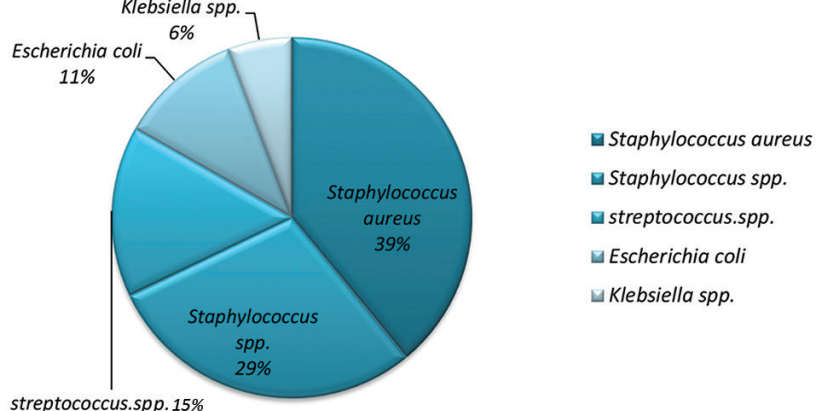

Fig. 1 Frequency of urinary tract pathogens in pregnant women.

socioeconomic conditions of the pregnant and the reinfection, when infection happened in the first trimester (some time it is possible in the third trimester) of pregnancy which was ensured by the patients' information.

One isolate of both $S$. aureus and E. coli had been chosen to continue and complete other steps of the study. These two isolates were subjected to standard tests for determination of their ability to produce different virulence factors such as hemolysin, protease, $\beta$-lactamase, adherence, and biofilm formation ability. From the result, it appeared that these two isolates gave positive results for the previous tests. Many studies indicate the relationship between the bacterial virulence factors and their pathogenicity such as Muder et al. ${ }^{27}$ who found that the bacteria which had the ability to produce hemolysin and protease enzymes in some way were showed to increase its invasion activity and ability to resist host immune system. While Al-Chalabi ${ }^{28}$ reported that several virulence factors such as hemolysin, cytotoxic necrotizing factor, aerobactin, biofilm, and different types of adhesion have been responsible for E. coli pathogenesis, because of the relationship between the bacterial ability to produce virulence factors and their infectivity or pathogenicity.

\section{Plant extracts}

Pomegranate peel extracts screening alkaloid, saponins, flavonoids, tannins, phenolic, glycosides, and resins as a phytochemical. The flavonoids and saponins were absent in aqueous extract, but during ethanol extraction, only saponins were not extracted. While in the acetone extraction this solvent succeeded to extract nearly all the studied active material. The antibacterial activity of plant extracts depends on the extraction conditions such as type and concentration of the solvent, time and temperature for the extraction process, all these factors effect on the type and the amount of the active material that extracted and found large amount of phytochemical material increase antibacterial activity of extract against pathogenic bacteria. ${ }^{29}$

3. The antibacterial activity of pomegranate peel extracts The results showed clearly that pomegranate peel extracts were active against $S$. aureus and $E$. coli bacteria in comparison to ciprofloxacin as a positive control and the distilled water as a negative control. The alcohol solvent could be considered as the best one among the three solvents which were used in this study. Acetone follow alcohol and distilled water might be the last good solvent with respect to their activity against the chosen isolates as shown in Tables 1 and 2. The result showed a relationship between the value of inhibition zone diameter for each one of the studied bacteria and type of solvents used in the extraction process. When the three solvents were used 


\begin{tabular}{lcccc}
\hline \multicolumn{1}{l}{ Table 1. Antibacterial activity of extracts against S. aureus bacteria } \\
\hline \hline
\end{tabular}

$\mathrm{LSD}_{0.05}$ (concentration $=0.064$, extraction solvent $=0.58$, interaction $\left.=1.296\right) . \mathrm{P} \leq 0.0001^{*}=$ significant different.

Table 2. Antibacterial activity of extracts against $\boldsymbol{E}$. coli bacteria

\begin{tabular}{|c|c|c|c|c|}
\hline \multirow[b]{2}{*}{ Concentration $\mathrm{g} / \mathrm{ml}$} & \multicolumn{3}{|c|}{ Inhibition zone rate $(\mathrm{cm})$} & \multirow[b]{2}{*}{ Concentration range } \\
\hline & $\begin{array}{c}\text { Aqueous pomegranate peel } \\
\text { extract }\end{array}$ & $\begin{array}{c}\text { Alcohol pomegranate } \\
\text { peel extract }\end{array}$ & $\begin{array}{l}\text { Acetone pomegranate } \\
\text { peel extract }\end{array}$ & \\
\hline 0.01 & $1.38^{*}$ & $1.50^{*}$ & $1.68^{*}$ & $1.52^{*}$ \\
\hline 0.025 & $1.51^{*}$ & $1.90^{*}$ & $1.76^{*}$ & $1.72^{*}$ \\
\hline 0.05 & $1.63^{*}$ & 1.93 & $1.91^{*}$ & $1.82^{*}$ \\
\hline 0.075 & $1.73^{*}$ & $2.08^{*}$ & $2.21^{*}$ & $2.01^{*}$ \\
\hline 0.1 & 1.78 & $2.36^{*}$ & 2.33 & $2.15^{*}$ \\
\hline Extraction Range & $1.64^{*}$ & $1.97^{*}$ & $1.98^{*}$ & \\
\hline $\begin{array}{l}\text { Control (Ciprofloxacin) } \\
\text { antibiotic } 5 \text { mg/disc }\end{array}$ & & 2.5 & & \\
\hline
\end{tabular}

$\mathrm{LSD}_{0.05}$ (concentration $=0.086$, extraction solvent $=0.077$, interaction $\left.=1.737\right) . P \leq 0.0001^{*}=$ significant different.

at different concentrations against $S$. aureus bacteria, alcohol solvent gave the widest inhibition zone, when used at 0.01 , $0.05,0.075$ and $0.1 \mathrm{~g} / \mathrm{ml}$ and it was followed by the value of inhibition zone diameter for the acetone extract, the aqueous extract had the lowest effect when used at the concentrations above and when $0.025 \mathrm{~g} / \mathrm{ml}$ concentration of these three types of extracts were used against $S$. aureus, the acetone extract was the best one as the highest effect then followed by the alcohol and the aqueous extracts. Among the solvent and according to their effects on $E$. coli isolate, acetone extract was considered as the best one when it used at $0.01 \mathrm{~g} / \mathrm{ml}$ and $0.075 \mathrm{~g} / \mathrm{ml}$, while the alcohol extract had the highest effect on E. coli bacteria at $0.025 \mathrm{~g} / \mathrm{ml}, 0.05 \mathrm{~g} / \mathrm{ml}$, and $0.1 \mathrm{~g} / \mathrm{ml}$ concentration in contrast with the other extracts.

When the pomegranate peel extracts were used as an antibacterial the best solvent chosen as extractor could be the polar solvents especially the ethanol solvent due to the best effect on both selected isolates. The results agree with Rathinamoorthy et $\mathrm{al} .{ }^{30}$ who attributed the antibacterial activity of pomegranate peel extracts to the presence of the broad spectrum antimicrobial compounds that act against both selected isolates.

\section{Antivirulence activity of pomegranate peel extracts}

The studied bacteria which had the ability to produce a number of virulence factors (hemolysin, protease, $\beta$-lactamase) were treated with the MIC of each one of the plant extracts (which reached to $0.006 \mathrm{~g} / \mathrm{ml}$ in aqueous extract, 0.004 in both alcohol and acetone extracts). The results explained that capacity of $S$. aureus and E. coli bacteria to produce hemolysin toxin and protease enzyme had not been affected and remained without any alteration after incubation period with these extracts compared to control. These bacteria completely lost their ability to produce $\beta$-lactamase enzymes after their treatment with the MIC of each extract, although these bacteria were active producer for this enzyme before they have been treated with the extracts, as shown in Table 3.

Forty cells of $S$. aureus bacteria adhered on the assayed epithelial cell, while only 20 cells of E. coli adhered to the epithelial cells. These data were regarded as control for detection the effects of the MIC of pomegranate peel extracts on adhesion ability of studied bacteria.

As shown in Fig. 2, the number of adhered S. aureus bacterial cells on the epithelial cell was clearly declined when the bacteria was treated with MIC of extracts. The aqueous extract reduced the number of the adherence bacterial to only 10 bacteria/cell, but the number of the adherence cells reached to 3 and 1 bacteria/cell in the presence of the acetone and the alcohol extracts, respectively.

The adherence of E. coli cell reached to one bacteria/cell when the acetone extract was added to bacterial suspension, but only three bacterial cells were seen to be attached to 


\begin{tabular}{|c|c|c|c|c|c|c|c|c|}
\hline \multirow[b]{2}{*}{ Virulence factors } & \multirow[b]{2}{*}{ S. aureus } & \multicolumn{3}{|c|}{ S. aureus with pomegranate peel extracts by } & \multirow[b]{2}{*}{ E.coli } & \multicolumn{3}{|c|}{ E. coli with pomegranate peel extracts by } \\
\hline & & Distill water & 96\% ethanol & $70 \%$ acetone & & Distill water & 96\% ethanol & $70 \%$ acetone \\
\hline Hemolysin & + & + & + & + & + & + & + & + \\
\hline Protease & + & + & + & + & + & + & + & + \\
\hline$\beta$-lactamase production & + & - & - & - & + & - & - & - \\
\hline
\end{tabular}

+ : indicates present, - : indicates absent.

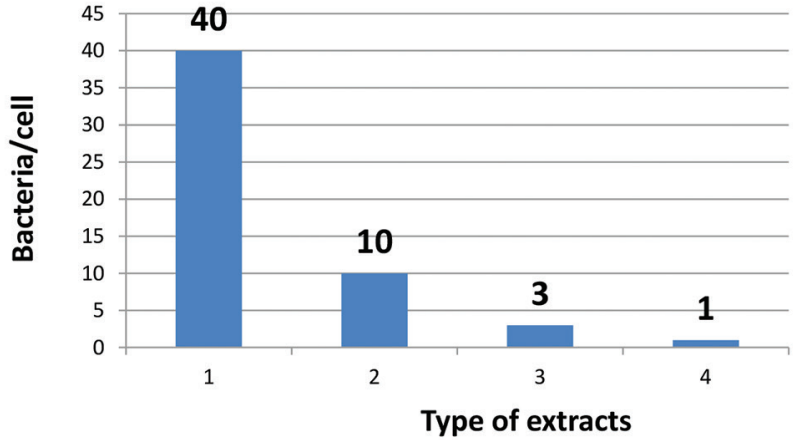

Fig. 2 Effects of extracts on adherence activity of S. aureus bacteria.

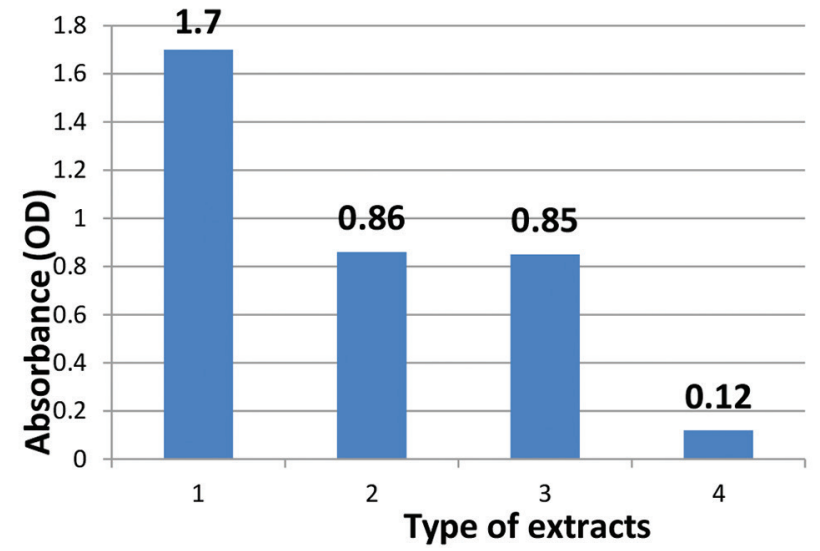

Fig. 4 Effects of extracts on biofilm formation activity of S. aureus bacteria.

epithelial cells after the bacterial suspension was incubated with alcohol extract, while only 5 bacteria/cell were attached after treatment with the aqueous extract, in contrast with control (E. coli without the extracts), as shown in Fig. 3.

As a comparison, ethanol extract was the best anti-adhesive factor, followed by acetone, while the aqueous extract had the least effect. This may return to the weak ability of distilled water to extract the active materials from plants peel in affected amounts compared to acetone and alcohol solvents.

The pomegranate peel extracts have been worked as anti-adhesive, because of the large amounts of the saponins, flavonoids, alkaloids, tannins, phenolic, glycosides, and resins, which were directly responsible for the anti-adhesive activity against the pathogen. ${ }^{31}$ The effect of the plant extracts is return to its ability to inhibiting cell attachment; therefore pretreatment of the body surface with plant extracts produced an unfavorable film that prevent and reduce the surface adhesion of pathogenic bacteria. ${ }^{32}$

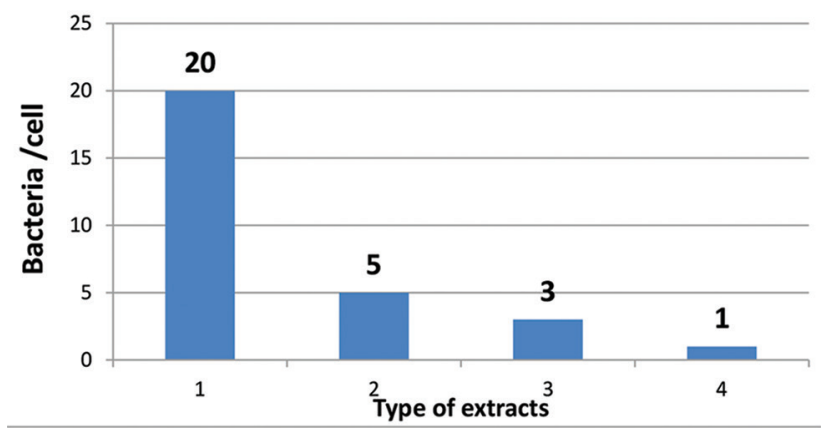

Fig. 3 Effects of extracts on adherence activity of $E$. coli bacteria.

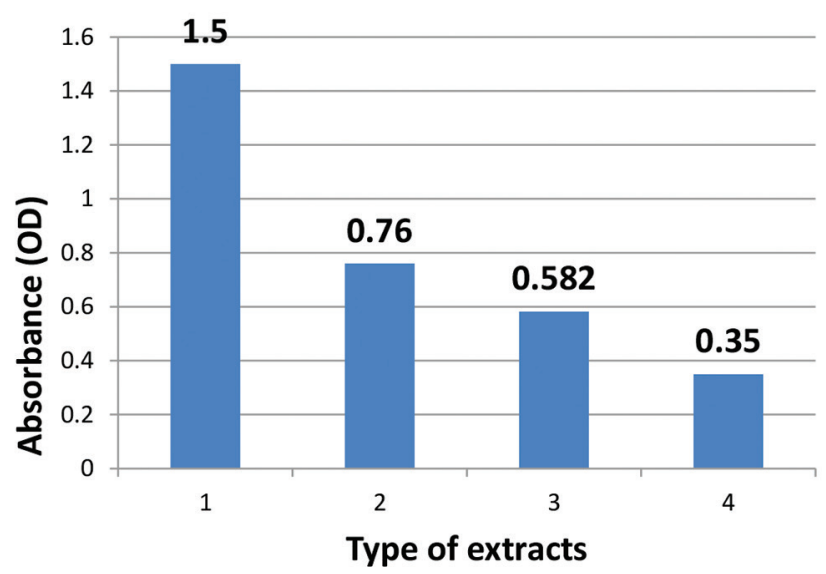

Fig. 5 Effects of extracts on biofilm formation activity of E. coli bacteria.

Figure 4 illustrates that $S$. aureus was a high producer for biofilm formation; this was shown through its optical density that reaches to 1.7 when it was measured for bacterial suspension without any types of the extracts (regarded as control). But, the optical density came to be reduced largely when the MIC of each one of the extracts was added to $S$. aureus suspension before reading the optical density. The optical density (OD) of S. aureus suspension with the MIC of the aqueous and the acetone extracts almost the same, and this result was different from the results of the other studies which found that the acetone extract had more effect than the aqueous extract. Whereas the alcohol extracts, still the best solvent in its effects on studied bacteria E. coli, was regarded as high producer biofilm because the OD of its suspension without extracts reached to 1.5. But when the suspension of E. coli bacteria was treated with MIC of the aqueous and acetone extracts, the OD of it reduced, which means the biofilm formation activity were declined clearly compared to the control, as shown in Fig. 5. 
The biofilm formation activity of bacteria were declined after treatment with extracts but this decline do not transfer bacteria from high producer (the control) to the poor producer (OD lower than 0.1) after treatment with extracts. $S$. aureus and E. coli bacteria were treated with the aqueous and the acetone extracts remained as a high producer (OD high than 0.5 ), but when bacteria was treated with alcohol extract it came to be transferred from high producer to producer only (OD between 0.5-0.1). This proved that alcohol solvent represented as the best solvent in extraction and preserves the activity of active compounds in pomegranate peel extracts compared with acetone and aqueous extracts. These results may be due to the formation of variety of biological properties and the activity of the extracts of chemical composition when different solvents were used in preparing these extracts. Many searchers were emphasizing by many trials to find some materials that inhibit the activity of virulence factors of pathogenic bacteria such as chemical material that was extracted from plants. ${ }^{33}$ The pomegranate peel extracts contain compound such as tannins that can interact with macromolecules, including carbohydrates and proteins, which made these compounds as promising anti-adhesive and antibiofilm. ${ }^{34}$

5. Interactions between the extracts and antibiotics in vitro The effect of the combination of the peel extracts and the antibiotics on the susceptibility of the $S$. aureus bacteria shown in Table 4 illustrated that the interaction of the ethanol extracts with the chloramphenicol and ciprofloxacin antibiotics were synergy. But with tetracycline it's been indifferent. While at the combination of the acetone extract with the three types of the antibiotics had been antagonism. The FIC value illustrated that the combination was indifference in the aqueous extracts with the chloramphenicol and ciprofloxacin antibiotics and came to be antagonism with the tetracycline antibiotic. While in the study of E. coli bacteria, susceptibility found that the synergy was present only in the interaction between the tetracycline and the acetone extract and the other results were divided between antagonism and indifference effect, but in the case of ethanol and the chloramphenicol it was additive (the effect which is less than synergistic but not antagonism), as shown in Table 5 .

The effect of chloramphenicol and ciprofloxacin antibiotics against $S$. aureus bacteria was marginally improved in the presence of the alcohol extract and the effect of the tetracycline antibiotic against $E$. coli was improved in the presence of the acetone extract, while any other combination between studied antibiotic and the extracts had not any beneficial effects against studied $S$. aureus and E. coli bacteria.

So the results found that the effect of pomegranate peel extracts alone was well than they interact with antibiotics in most of the results. While other studies found that the efficacy of antimicrobial agents could be improved by combining antibiotics with crude plant extracts against different pathogens

\begin{tabular}{|c|c|c|c|c|c|}
\hline Antibiotics & Pomegranate extract & Mean FIC (antibiotic) & Mean FIC (extract) & FIC index & Interaction \\
\hline & Ethanol 96\% & 0.1 & 0.1 & 0.2 & Synergy \\
\hline \multirow[t]{3}{*}{ Chlo } & Acetone $70 \%$ & 0.9 & 1.125 & 2.025 & Antagonism \\
\hline & D.W. & 0.5 & 0.833 & 1.33 & Indifference \\
\hline & Ethanol 96\% & 0.1 & 0.1 & 0.2 & Synergy \\
\hline \multirow[t]{3}{*}{ Cip } & Acetone $70 \%$ & 1.8 & 0.937 & 2.73 & Antagonism \\
\hline & D.W. & 1.2 & 0.833 & 1.93 & Indifference \\
\hline & Ethanol 96\% & 0.375 & 0.75 & 1.125 & Indifference \\
\hline \multirow[t]{2}{*}{ Tet } & Acetone $70 \%$ & 0.375 & 0.937 & 1.31 & Antagonism \\
\hline & D.W. & 0.45 & 1.5 & 1.95 & Antagonism \\
\hline
\end{tabular}

Chlo: chloramphenicol, Cip: ciprofloxacin, Tet: tetracycline.

\begin{tabular}{|c|c|c|c|c|c|}
\hline Antibiotics & Pomegranate extract & Mean FIC (antibiotic) & Mean FIC (extract) & FIC index & Interaction \\
\hline & Ethanol 96\% & 0.5 & 0.5 & 1 & Additive \\
\hline \multirow[t]{3}{*}{ Chlo } & Acetone $70 \%$ & 0.75 & 0.937 & 1.68 & Indifference \\
\hline & D.W. & 0.75 & 1.25 & 2 & Antagonism \\
\hline & Ethanol 96\% & 1.125 & 0.9 & 2.025 & Antagonism \\
\hline \multirow[t]{3}{*}{ Cip } & Acetone $70 \%$ & 0.625 & 0.625 & 1.25 & Indifference \\
\hline & D.W. & 0.937 & 1.25 & 2.187 & Antagonism \\
\hline & Ethanol 96\% & 0.375 & 0.75 & 1.125 & Indifference \\
\hline \multirow[t]{2}{*}{ Tet } & Acetone $70 \%$ & 0.25 & 0.625 & 0.875 & Synergy \\
\hline & D.W. & 0.375 & 1.25 & 1.625 & Indifference \\
\hline
\end{tabular}

Chlo: chloramphenicol, Cip: ciprofloxacin, Tet: tetracycline. 
in vitro and found that it may reduce MICs of antibiotics against resistant organisms. The combination of the plants extracts and the antibiotics could be useful in fight emergency drug resistance pathogens. ${ }^{35}$

The antimicrobial compounds extracted from plants have been found to be synergistic enhancers in that though they may not explain any antimicrobial properties alone, but when used with antibiotic they enhance the activity of the drug. The synergistic effect of the association of antibiotic and plant extracts against resistant pathogens leads to new choices for the treatment of infectious diseases. Also synergy between plant product and drug will solve problems of toxicity and overdose since when they combine a little concentration of two agents is required. Therefore, there is an urgent need to find source of natural compound to solve the problem of multiple drug resistance. ${ }^{36}$

\section{References}

1. Haider G, Zehra N, Munir AA, Haider A. Risk factors of urinary tract infection in pregnancy. J Pak Med Assoc. 2010 Mar;60(3):213-6. PMID: 20225781

2. Nahar SJ, Khanum H, Shimasaki K. Occurrence of Escherichia coli infection among the women of Dhaka city. ARPN J Agricultural Bio Sci. 2010 Nov; $5(6): 68-73$

3. Sawalha RMH. Prevalence of urinary tract infection among children of primary schools in Nablus, M.Sc. Thesis. An-Najah National Univ. of Nablus, Palestine; 2009.

4. Umar N, Basavaraj S. Sirwar. Prevalence of urinary tract infection in pregnant women. J Evolution of Med Dent Sci. 2012;1(4):315-20

5. Ali MM. Evaluation of antimicrobial susceptibility \& rapid urine screening tests in asymptomatic urinary tract infection in pregnant women in Karbala. K J Pharm Sci. 2011;2:22-34

6. Akindele AA, Adewuyi IK, Adefioye OA, Adedokun SA, Olaolu AO. Antibiogram and beta-lactamase production of Staphylococcus aureus isolates from different human clinical specimens in a Tertiary Health Institution in Ile-ife, Nigeria. American-Eurasian J Sci Res. 2010;5(4):230-3.

7. Atabek A. Investigating bacterial outer membrane polymers and bacterial interactions with organic molecules using atomic force microscopy, Master's Thesis. Worcester Polytechnic Institute, MA, USA

8. Hola V, Ruzicka F, Votava M. The dynamics of Staphylococcus epidermis biofilm formation in relation to nutrition, temperature and time. Scripta Medica (BRNO) 2006;79(3):169-74

9. Aiyegoro O, Adewusi A, Oyedemi S, Akinpelu D, Okoh, A. Interactions of antibiotics and methanolic crude extracts of Afzelia Africana (Smith.) against drug resistance bacterial isolates. Int J Mol Sci. 2011;12:4477-503.

10. Dahham SS, Ali MN, Tabassum H, Khan M. Studies on antibacterial and antifungal activity of pomegranate (Punica granatum L.). AmericanEurasian J Agric \& Environ Sci. 2010;9(3):273-81.

11. Endo EH, Ueda-Nakamura T, Nakamura CV, Filho BPF. Activity of spraydried micro particles containing pomegranate peel extract against Candida albicans. Molecules. 2012 Aug;17:10094-107. doi: http://dx.doi. org/10.3390/molecules170910094 PMID: 22922280

12. Collee JG, Fraser AG, Marmion BP, Simmons A. Mackie and McCartney. Practical medical microbiology, $14^{\text {th }}$ ed. UK: The Churchill Livingstone. Inc. 1996. pp. 329-41.

13. Baron EJ, Peterson LR, Finegold SM. Bailey \& Scott's diagnostic microbiology, 9th ed. USA: Mosby-Year Book; 1994.

14. Mathur T, Singhal S, Khan S, Upadhyay DJ, Fatma T, Rattan A. Detection of biofilm formation among the clinical Isolates of Staphylococci: an evaluation of three different screening methods. Indian J Med Microbiol. 2006;24(1):25-30. doi: http://dx.doi.org/10.4103/0255-0857.19890 PMID: 16505551

15. WHO. Techniques for the detection of $\beta$-lactamase producing strains of Neisseria gonorrhoeae. 1978;616:137-43.

16. Eden CS, Eriksson B, Hanson LA. Adhesion of Escherichia coli to human uroepithelial cells in vitro. Infect Immun. 1977 Dec;18(3):767-74.

17. Maldonado NC, Silva de Ruiz C, Cecilia M, Nader-Macias ME. A simple technique to detect Klebsiella biofilm-forming-strains. Inhibitory potential of Lactobacillus fermentum CRL 1058 whole cells and products. Communicating Current Research and Educational Topics and Tends in Applied Microbiology A. Mendez Vilas (Ed); 2007.

18. Ahmad I, Mehmood Z, Mohammad F. Screening of some Indian medical plants for their antimicrobial properties. J Enthnophar. 1998;62(2):183-93. doi: http://dx.doi.org/10.1016/s0378-8741(98)00055-5

19. Al-Jboriy KA, Al-Anasary BS, Ali HSA. Study of the sensitivity of some pathogenic isolated from respiratory infection in human against same plant extracts. Anbar J Veterinary Sci. 2010;3(2):103-8.

20. Egharevba HO, Kunle OF, Iliya I, Orji PN, Abdullahi MS, Okwute SK, et al. Phytochemical analysis and antimicrobial activity of Punica granatum L. (fruit bark and leaves). New York Sci J. 2010;3(12):91-8.

21. CLSI. Methods for dilution antimicrobial susceptibility tests for bacteria that grow aerobically; Approved Standard-Ninth Edition. CLSI document M07-A9. Wayne, PA: Clinical and Laboratory Standards Institute; 2012

22. Ling YC, Feng XS, Xia G. Preliminary phytochemical analysis of Acanthopanan trifoliatus (L.) Merr. J Med Plants Res. 2011 Sept 9;5(17):4059-64

23. Mandal S, Mandal MD, Pal N. Evaluation of combination effect of ciprofloxacin and cefazolin against Salmonella enterica serovar typhi isolates by in vitro methods. Calicut Med J. 2004;2(2):e2.

24. Kamatou GPP, Viljoen AM, van Vuuren SF, van Zyl RL. In vitro evidence of antimicrobial synergy between Salvia chamelaeagnea and Leonotis leonurus. SA J Bot. Nov 2006;72(4):634-6. doi: http://dx.doi.org/10.1016/j. sajb.2006.03.011

25. Pankey G, Ashcraft D, Patel N. In vitro synergy of daptomycin plus rifampin against Enterococcus faecium resistant to both linezolid and vancomycin Antimicrob Agents Chemother. 2005 Dec;49(12):5166-8. doi: http://dx.doi. org/10.1128/aac.49.12.5166-5168.2005 PMID: 16304195

26. SAS. SAS/STAT User's Guide for Personal Computers. Release 6.12. NC, USA SAS Inst. Inc:; 2012

27. Muder RR, Brennen C, Rihs JD, Wagener MM, Obman A, Stout JE, Yu VL. Isolation of Staphylococcus aureus from the urinary tract: association of isolation with symptomatic urinary tract infection and subsequent Staphylococcal bacteremia. Clin Infect Dis. 2012 Jan 1;42(1):46-50. doi: http://dx.doi.org/10.1086/498518 PMID: 16323090

28. Al-Chalabi R, Al-Ubaidy A, Al-Ibadi M. Detection of urovirulence genes (eae, E-hly, a-hly) of uropathogenic Escherichia coli by specific PCR. J Biot Res Center. 2010;4(1):44-54

29. Kdhim ZR. Extraction and purification of flavonoids from Camellia sinesis leaves and Punica granatum peels and determination of their antioxidant activity, M.Sc. Thesis. Karbala Univ; 2012.

30. Rathinamoorthy R, Udayakumar S, Thilagavathi G. Antibacterial efficacy analysis of Punica granatum $\mathrm{L}$. leaf, rind and Terminalia chebula fruit extract treated cotton fabric against five most common human pathogenic bacteria. Int J Pharm \& Life Sci. 2011 Oct;2(10):1147-53.

31. O'Mahony R, Al-Khtheeri H, Weerasekera D, Fernando N, Vaira D, Holton J, et al. Bactericidal and anti-adhesive properties of culinary and medicinal plants against Helicobacter pylori. World J Gastroenterol. 2005 Dec 21;11(47): 7499-507. PMID : 16437723

32. Sandasi $M$, Leonard CM, Viljoen $A M$. The in vitro antibiofilm activity of selected culinary herbs and medicinal plants against Listeria monocytogenes. Lett Appl Microbiol. 2010 Jan;50(1):30-5. doi: http:// dx.doi.org/10.1111/j.1472-765X.2009.02747.x PMID: 19874481

33. Jiang P, Li J, Han F, Duan G, Lu X, Gu Y, Yu W. Antibiofilm activity of an exopolysaccharide from marine bacterium Vibrio sp. QY101. PLoS One. 2011 Apr 7;6(4):e18514. doi: http://dx.doi.org/10.1371/journal.pone.0018514 PMID: 21490923

34. Janecki A, Kolodziej H. Anti-adhesive activities of flavan-3-ols and proanthocyanidins in the interaction of group A-streptococci and human epithelial cells. Molecules 210 Oct 15;15(10):7139-52. doi: http://dx.doi. org/10.3390/molecules15107139 PMID: 20953158

35. Adwan G, Mohammad Mhanna M. Synergistic effects of plant extracts and antibiotics on Staphylococcus aureus strains isolated from clinical specimens. Middle-East J Scientific Res. 2008:3(3):134-9.

36. Aiyegoro OA, Okoh Al. Use of bioactive plant products in combination with standard antibiotics: implications in antimicrobial chemotherapy. J Med Plants Res. 2009 Dec;3(13):1147-52. 